\title{
Optimising building sustainability assessment using BIM
}

\author{
José Pedro Carvalho*, Luís Bragança, Ricardo Mateus \\ University of Minho, School of Engineering, Civil Engineering Department, Guimarães, Portugal
}

\section{A R T I C L E I N F O}

\section{Keywords:}

Building information modelling (BIM)

Building sustainability assessment (BSA)

Sustainability

SBTool

\begin{abstract}
A B S T R A C T
The construction industry is responsible for various negative impacts on the environment leading to an increasing demand for sustainable buildings. There are several Building Sustainability Assessment (BSA) methods that allow designers to assess and optimise the building sustainability level. Due to the potential of Building Information Modelling (BIM), the opportunity for BSA methods to adopt and benefit from BIM arises. Despite the benefits in the approach simplification for assessing building sustainability, so far the method has not been used comprehensively in the evaluation process. This paper analyses how using BIM can contribute to optimising BSA methods, focusing on the SBTool ${ }^{\mathrm{PT}}$-H. BIM applicability is assessed and a framework for a BIM-based application - SBTool ${ }^{\mathrm{BIM}}$ - is proposed. BIM is still not oriented to sustainable building, but it has great potential. For the SBTool $^{\mathrm{PT}}-\mathrm{H}$, results show that it is possible to directly and indirectly assess 24 out of 25 criteria using BIM.
\end{abstract}

\section{Introduction}

\subsection{Sustainability and building sustainability assessment (BSA) methods}

Over recent decades, there has been increasing concern about the impact of buildings on the environment $[1,2]$. The relation between environmental problems and the construction industry has already been proven and accepted by the scientific community [3-5]. Nowadays, the Architecture, Engineering, and Construction (AEC) industry is responsible for $40 \%$ of the total energy use, $32 \%$ of $\mathrm{CO}_{2}$ emissions and $25 \%$ of the generated waste in Europe on an annual basis. In this context, public authorities and the society, in general, have shown particular interest for more sustainable, efficient and ecological buildings and building technologies [6].

The definition of the concept of sustainable development has been widely discussed and updated over the last years [7]. In 1987, the Brundtland report (Our Common Future) established sustainable development as "...the development that meets the needs of the present without compromising the ability of future generations to meet their own needs" [8]. This goal was also defined as a priority in the AEC industry since the conventional way to design, build, operate and demolish a building is normally responsible for using large amounts of non-renewable materials, energy and for producing huge amounts of waste $[9,10]$.

Following the two first United Nations main conferences about the Environment and Sustainable Development (Rio de Janeiro, 1992 and Johannesburg, 2002), three main dimensions for sustainable development and construction were established: Environmental dimension, Economic dimension and Social-cultural dimension $[7,10]$.

The first definition of sustainable construction was provided by Charles Kibert in 1994 during the First World Conference on Sustainable Construction (Florida). He defined it as the "responsible creation and management of a healthy building environment, considering the ecological principles and the efficient use of resources". The following 6 principles were established for a sustainable construction [11]:

- Minimise resource consumption;

- Maximise resource reuse;

- Use renewable or recyclable resources;

- Protect the natural environment;

- Create a healthy and non-toxic environment;

- Pursue quality in creating the built environment.

Due to the identified concerns, there was a need to evaluate the impact of buildings on the environment. Therefore, several organisations developed Building Sustainability Assessment (BSA) methods in order to implement and spread sustainable measures in construction projects, evaluate and monitor buildings performance and gather information to support designer's decision making in the different stages of a project $[12,13]$. The use of BSA methods provides an opportunity for design teams to demonstrate the environmental, economic and social benefits of the buildings they design to the local community [14].

During the past two decades, several BSA methods have been developed all over the world by private companies and public

\footnotetext{
* Corresponding author.

E-mail addresses: jpcarvalho@civil.uminho.pt (J.P. Carvalho), braganca@civil.uminho.pt (L. Bragança), ricardomateus@civil.uminho.pt (R. Mateus).
} 
organisations or authorities [12]. Some methods were developed with the purpose of being used all over the world and, others were developed or adapted to suit the specific environmental, economic and socio-cultural characteristics of a certain region $[13,15]$. These methods are usually characterised by assessing a number of partial building features and aggregating the results into an environmental rating or sustainability score [12].

The first known BSA method, BREEAM (Building Research Establishment Environmental Assessment Method), dates back to 1990 and it was established by the Building Research Establishment (BRE) in the United Kingdom. This BSA method together with the SBTool (Sustainable Building Tool), developed by the International Initiative for a Sustainable Built Environment (iiSBE) and LEED (Leadership in Energy and Environmental Design), developed by the United States Green Building Council (USGBC), provide the basis for all the other approaches used throughout the world $[12,15]$.

This study aims to evaluate how the BIM methodology can contribute to optimising, simplifying and automating Building Sustainability Assessment methods. The above evaluation will consider a Portuguese BSA method - SBTool ${ }^{\mathrm{PT}}-\mathrm{H}$ - and a framework for a BIMbased end-user application to optimise the assessment process.

\section{2. $S B$ Tool $^{P T}-H$}

This paper focuses on the analysis of the $\mathrm{SBTool}^{\mathrm{PT}}-\mathrm{H}$ method that resulted from adapting the international Sustainable Building Tool (SBTool) to the context of Portuguese residential buildings. The SBTool is considered the most comprehensive of all the BSA methods [15] and has the flexibility to be adjusted to the local conditions of each region $[12,15]$. This feature allows this method to be used to compare the sustainability of buildings from different countries.

The SBTool ${ }^{\mathrm{PT}}-\mathrm{H}$ has been developed with the purpose of creating a generic methodology to assess the sustainability of existing, new and renovated Portuguese buildings. Besides the sustainability assessment, the method is also targeted to support design teams since the early stages of a project and to raise awareness of construction market's stakeholders about the individual and global benefits of adopting more sustainable solutions [12].

In the SBTool ${ }^{\mathrm{PT}}-\mathrm{H}$ the three dimensions of sustainable development are considered - Environment, Society and Economy. Each dimension is defined by categories, which in turn is defined by sets of sustainability criteria, as presented in Table 1.

The SBTool ${ }^{\mathrm{PT}}-\mathrm{H}$ has a total of twenty-five sustainability criteria, which can be found in Table 2. The number and nature of the criteria vary from one category to another according to the priority of sustainable development that is expressed by the category and its importance to the Portuguese context. Each sustainability criterion has a different weight according to the national standards and practices. Each criterion is classified with a quantitative "score" that results from the comparison between two benchmarks: best and conventional sustainability practice. After weighing all the criteria, a final sustainable classification is given to the building [12].
Nowadays, assessing a building using the $\mathrm{SBTool}^{\mathrm{PT}}-\mathrm{H}$ method is a time-consuming and inefficient process, as it requires several data and calculations and is mostly based on an interactive process that seeks to find the design approach that results in the targeted sustainability level. The use of SBTool ${ }^{\mathrm{PT}}-\mathrm{H}$ is usually incompatible with tight deadlines of the design phase, making it difficult to use. Furthermore, project teams are discouraged from improving the sustainability level of their projects, since any project modification will result in repeating the entire assessment process.

Using Building Information Modelling (BIM) can streamline and reduce the time needed to perform an assessment using $\mathrm{SBTool}^{\mathrm{PT}}-\mathrm{H}$. The faster data assessment and the whole-building analysis allowed by BIM can support designers in decision making when different sustainable measures are introduced. By reducing the time needed to perform the assessment and the integration in a BIM workflow an opportunity will be created to introduce the SBTool ${ }^{\mathrm{PT}}-\mathrm{H}$ in Portuguese AEC companies. This will promote the development of buildings with higher performance than the conventional practice, thus contributing to a more sustainable built environment.

\subsection{Building information modelling (BIM)}

Construction projects are becoming more difficult and complex [16]. In order to optimise, automate and modernise the traditional processes of the AEC industry, Building Information Modelling (BIM) has emerged and it is already changing the current scenario of construction projects. Due to its advantages compared to the traditional design approaches, there are several design teams, in different countries, using this method. Furthermore, some countries are promoting its use as a conventional design practice. For example, in the United Kingdom, since the beginning of 2016, it is mandatory to use BIM in all public projects [16].

The BIM concept can be defined as a set of policies, processes, and technologies which conceive a working methodology, making it possible to manage 3D drawings and other project data in a digital format, during the entire building life cycle. It is an integrated process where the functional and physical characteristics of a project are managed, digitally simulating the real construction of the project [17]. This paradigm change will have impacts and benefits not only for the construction sector but also for the society in general, such as better constructions which consume fewer materials, require less human and financial resources and operate more efficiently [18].

The essence of BIM lies in the project stakeholders sharing information during the whole building lifecycle. When compared to the traditional approach (Fig. 1), which is sequential, disorganised and lacks information sharing, BIM allows each stakeholder to work individually but always connected to a central model, that contains all building related information, namely the architectural and technical/ engineering projects. This allows designers to quickly identify errors and incompatibilities, facilitating decision making, as well as optimising costs and time [16].

When applied to a construction project, this methodology results in

Table 1

$\mathrm{SBTool}^{\mathrm{PT}}-\mathrm{H}$ list of categories.

\begin{tabular}{llcc}
\hline Dimension & Category & Number of criteria & Dimension weight (\%) \\
\hline Environment & C1 - Climate change and outdoor air quality & 1 & 40 \\
& C2 - Land use and biodiversity & 5 & \\
& C3 - Energy Efficiency & 5 & \\
C4 - Materials and waste management & 2 & \\
Social & C5 - Water efficiency & 5 & 30 \\
& C6 - Occupant's health and comfort & 2 & \\
Economic & C7 - Accessibilities & 1 & 30 \\
\hline
\end{tabular}


a virtual model (BIM model) that contains all the project characteristics. This model is developed by an object-oriented parametric modulation which means that parameters are defined to characterise the relation between objects (such as beams, columns, ducts, pipes, etc.). Depending on the purpose of the model, objects must have a certain Level of Development (LOD) in order to carry out the required operations. The LOD describes the amount and type of information contained in a BIM model. It ranges from LOD 100, the conceptual project model, to LOD 500, the as-built model. To create the virtual model, it is recommended using a BIM platform - software that generates multiple uses information and creates and edits BIM models.

After the modulation, the BIM model can be used throughout the entire building life cycle: visualisation, documentation, management, cost planning, maintenance, operation, detailed analysis, logistics, demolition, etc. $[16,20]$. Most of these uses require additional BIM tools different types of software that perform a specific type of analysis. Exchanging information between these tools and the BIM platform can be done in different ways. Depending on the analysis objective, different exchange file formats such as Industry Foundation Classes (IFC) and Green Building XML (gbXML) can be used. For some BIM platforms and tools, direct links to connect them already exist.

Despite all the BIM benefits, only $36 \%$ of construction companies in Western Europe are using it [21]. This fact can be explained by the difficulty of adopting new methodologies inside companies, mainly due to the change resistance from traditional methods empowered by the lack of knowledge on the subject [22]. Other possible reasons may be the high investment needed in software and professional qualification, which also leads to a productivity loss during the adaptation phase. Interoperability matters between software and the lack of normalisation also contribute negatively to the BIM implementation [20,22,23].

\subsection{Sustainability of the construction sector and BIM}

Due to the need of providing adequate answers to the increasing demand for sustainable buildings, several processes and technologies have been developed with the purpose of reducing energy needs, project costs, construction period, $\mathrm{CO}_{2}$ emissions, waste, etc. [24,25]. Among those, BIM is a method that is emerging. By allowing multidisciplinary information to be overlaid and grouped into a single model, BIM creates an excellent opportunity to incorporate sustainable measures throughout the different stages of a project [26].

In 2008, Krygiel and Nies [27] listed the main aspects where BIM can be applied with the purpose of improving the sustainability level of a project:

- Building orientation;

- Building massing;

- Daylight analysis;

- Water harvesting;

- Renewable energy;

- Energy modelling;

- Sustainable materials.

BIM methodology can also offer other capabilities, which can be directly or indirectly linked to sustainability as [28]:

- Automatic and accurate bill of materials and cost estimations;

- Reduction of resource use;

- Construction/deconstruction/rehabilitation waste management;

- Automatic update of project modifications;

- Facilitates the implementation of lean construction techniques.

Based on the capabilities presented before, when using BIM, designers are provided with detailed information in order to select the best sustainable solutions for the building. The use of BIM technologies has the potential to change the AEC traditional practices, allowing for the efficient development of high-performance buildings and, therefore, more sustainable ones. Additionally, a study conducted by Azhar et al [26] on the University of South Carolina Campus, used BIM to improve the sustainability level of the project. The results showed savings of $20 \%$ on the total cost of the project $(900,000$ USD) over a 10 -year period.

According to Azhar et al [29], the pre-construction and project phases are the critical ones, where decisions regarding building sustainability are supposed to be made. Since this is also the phase when projects can most benefit from BIM, the influence that it can have on the sustainability of buildings becomes clear.

A study carried out by Wong and Zhou [14] concluded that BSA methods should be used from the preliminary design stages, so that the process of sustainable design will become more efficient and cost-effective, creating a greater impact on the construction project. The same study also proposed that BIM should be used together with a BSA method in order to obtain more reliable and concise results. Despite BIM being extremely useful during the design stages, several authors argue that the BIM method should also be used during the following lifecycle stages of a building, including operation, repair, maintenance, and demolition in order to take full advantage of using it to promote efficient and high-performance buildings [14,23].

Despite all the benefits, the application of BIM in BSA methods has not been clearly defined yet. Some authors point out the following as possible reasons: the lack of data obtained from BIM platforms and tools to be used in the sustainability assessments, as well as the lack of embodied tools to assess the sustainability level, based on the methodology of most common BSA methods $[15,26,30]$. Therefore, they suggest that future platforms and/or tools should be further developed to cover more parameters and aspects related to sustainable issues.

Nevertheless, some steps have already been implemented by Azhar et al [26], which have developed and validated a conceptual structure to establish the connection between the data gathered by the BIM method and the necessary data for the LEED certification process. The results showed that some of the parameters needed for the sustainability assessment could be directly or indirectly gathered using the results from Autodesk Revit and IES VE software. They also concluded that this process has the capacity to simplify the LEED certification while saving time, costs and resources. However, this study was only applied to 17 out of 29 LEED criteria and 2 out of 3 pre-requisites, and therefore, more comprehensive studies regarding the remaining LEED credits should be carried out. Another study, developed by Wong and Kuan [2], tested the usefulness of the BIM method to obtain the necessary parameters to assess the sustainability level of buildings using the BSA method BEAM Plus. The results showed that 26 out of 56 criteria can be obtained much faster and with fewer resources with the support of BIM when compared to the traditional methods. Based on this context, a review study from Chong [31] concluded that future BIM standards should include a set of requirements for a building sustainability assessment.

According to the capabilities mentioned and existing proposals, it is consistent to affirm that BIM can become an essential tool for developing more sustainable buildings, by effectively acting on the main dimensions of sustainable construction: environment, society and economy.

\subsection{Autodesk Revit's application programming Interface (API)}

The Application Programming Interface (API) works as an intermediary to different software or applications in order to allow the exchange of information. It defines the procedure to request services or information from a software or application [32,33].

"APIs are made up of two related elements. The first is a specification that describes how information is exchanged between programs, done in the form of a request for processing and a return of the necessary data. The second is a software interface written to that specification and published in 
some way for use" [32]. There are three types of APIs: Local API, the original form, which offers operating systems or middleware services to application programs; Web API, which represents widely used resources such as HTML pages and is assessed using simple HTTP protocol. These APIs are often called REST or RESTful; and Program API, based on Remote Procedure Call (RPC) technology that makes a remote program component appear to be local to the rest of the software.

Autodesk Revit API is designed to reflect the same user interaction paradigms as the program's Graphical User Interface. It allows the user to program with any. NET compliant language including Visual Basic.NET, C\# and C + + /CLI. Autodesk Revit API is suitable to be used in the following areas [34]:

- Creating add-ins and macros to automate repetitive tasks in the Autodesk Revit user interface;

- Enforcing project design standards by checking for errors automatically;

- Extracting project data for analysis and to generate reports;

- Importing external data to create new elements or parameter values;

- Integrating other applications, including analysis applications, into Autodesk Revit products;

- Creating Autodesk Revit project documentation automatically.

Autodesk Revit API has been generally used in the AEC industry to perform and improve several types of analysis. Oti, Tizani et al $[35,36]$ used Autodesk Revit API to appraise alternative steel-framed building design solutions using multi-criteria performance analysis. The intention was to support structural engineers in assessing the sustainability measures of alternative design solutions at the early design stages. The life cycle approach was used to explore costs, as well as the carbon and ecological footprint.

Pereira and Amorim [37] have created VeR_Arq to improve project quality, information exchange and control. The aim was to automate and systemise a validation procedure to check project biosecurity and legal standards in laboratory animal facility projects.

Kim et al [38] and Kota et al [39] have created two prototypes Revit2Modelica and Revit2Radiance - for thermal and daylight simulations. The goal was to optimise the flow of information between Revit-Modelica and Revit-Radiance/DAYSIM. Despite the good results achieved, the authors recognised slight differences between Revit2Modelica and the validation engine: The Lawrence Berkeley National Laboratory (LBNL) Modelica Buildings Library, which was validated using the ANSI/ASHRAE Standard 140-2007. Further validation is also needed for Revit2Radiance API prototype as only geometry and materials were checked. The research has identified that BIM does not have all the necessary information for Radiance and DAYSIM. However, it provides options to incorporate the required information.

Jalaei and Jrade [40] have developed a methodology to integrate BIM with LEED-NC to automatically calculate Energy and Atmosphere and Material and Resources credits. Autodesk Revit API was needed to calculate the soft cost that includes the fees required to register and to obtain the LEED certification for the proposed sustainable building. The authors proposed using the Google Maps API to calculate the distance between the location (origin) of the materials suppliers and the location of the project (destination). These authors demonstrated that BIM and LEED integration was feasible but with considerable constraints, as it does not analyse the costs associated with different materials or systems that can be used to attain each credit or point.

Cheng and Ma [41] have created a BIM-based system for estimating and planning Demolition and Renovation Waste in the context of Hong Kong. Autodesk Revit API was used to extract material and volume information and to integrate the information for detailed waste estimation. Automated, fast and accurate waste estimation can be achieved using this system. The system also considered waste recycling and reuse.

Some recognised simulation software, such as DesignBuilder, IES VE or Dynamo also have their own Autodesk Revit API to improve information exchange with Autodesk Revit and saves users' time.

\section{Methodology}

As mentioned before, the aim of this work is to assess how the data provided by BIM platforms and tools can contribute to optimising, simplifying and automating Building Sustainability Assessment (BSA) methods. A problem-oriented approach will be used, since the goal is to find a practical solution for a practical problem - developing a method that simplifies and optimises the BSA using the BIM approach. For this purpose, a Portuguese BSA method - SBTool ${ }^{\mathrm{PT}}-\mathrm{H}$ - will be considered as the case study and will be studied in order to evaluate the potential of BIM in assessing the sustainability criteria. Therefore, a theoretical analysis covering each criterion of the mentioned BSA method will be implemented, focusing on how each one can be directly or indirectly evaluated using one BIM process and how much the assessment process could be optimised and simplified. To achieve this goal, as a first stage, each sustainability criterion will be studied to identify the necessary data for the assessment and the BIM process that could be used to gather the required information. The study will consider Autodesk Revit as a BIM modelling platform since it is one of the most used in the AEC industry. The existing Autodesk Revit APIs (such as DesignBuilder or Dynamo) and the possibility to import and export several format types, which include IFC and gbXML, will optimise information exchange and software interoperability. Several online tutorials also helped in selecting Autodesk Revit [42,43].

In the following stage, based on the results of the previous analysis, the applicability of BIM to optimise the SBTool ${ }^{\mathrm{PT}}-\mathrm{H}$ assessment process will be assessed. At the end, an application framework for developing a BIM-based end-user application - SBTool ${ }^{\mathrm{BIM}}$ - will be proposed, according to the capabilities and restrictions of BIM and $\mathrm{SBTool}^{\mathrm{PT}}-\mathrm{H}$. The suggested framework will define the BIM model details for each stage of the evaluation, identify the need to collect external information, the sequence of tasks and processes, the interoperability between platforms/tools, the predicted limitations, and indications on how to obtain and aggregate the results from the BIM platforms and tools. The aim is to match the framework with BIM platform Autodesk Revit, as it is one of the most used BIM platforms, as well as with the Application Programming Interface (API) functions, which serve as intermediary links to allow communication between different software. The research procedure is summarised in Fig. 2.

\section{Results and discussion}

The BSA method SBTool ${ }^{\mathrm{PT}}-\mathrm{H}$ is based on assessing 25 sustainability criteria, covering the three dimensions of sustainable development: Environment; Society; and Economy. Table 2 presents an overview of the potential of Autodesk Revit and additional BIM tools to fully (F) or partially (P) evaluate each SBTool ${ }^{\mathrm{PT}}$-H criterion. All the additional BIM tools mentioned can perform specific analysis for the assessment by importing Autodesk Revit models with IFC, gbXML or direct links. Additionally, the necessary model details and the User Interference (UI) need to collect external information, as regulatory or legislative data are also discussed. Whenever it is not possible to use a BIM methodology/process to aid the criterion evaluation, a way to support designers to access the information that they need is suggested.

From the analysis in Table 2, it can be concluded that BIM can fully support the evaluation of 15 out of the 25 criteria from the SBTool ${ }^{\mathrm{PT}}-\mathrm{H}$. It has also been found that BIM can potentially help to some extent in gathering part of the required information to assess the other 9 remaining criteria. Despite that, for some criteria, it is still necessary to use the user knowledge and efforts to collect some of the required information. It has also been found that the assessment of the sustainability criteria related to amenities and accessibility will not benefit much from BIM if the neighbourhood is not modelled. Concerning Autodesk Revit as a BIM platform, it can provide the necessary information to fully assess 8 criteria and partially assess 3 criteria. As Autodesk Revit allows to create and edit the BIM model, 13 criteria can be partially or fully assessed when the model is exported to the additional software (at least 6). 


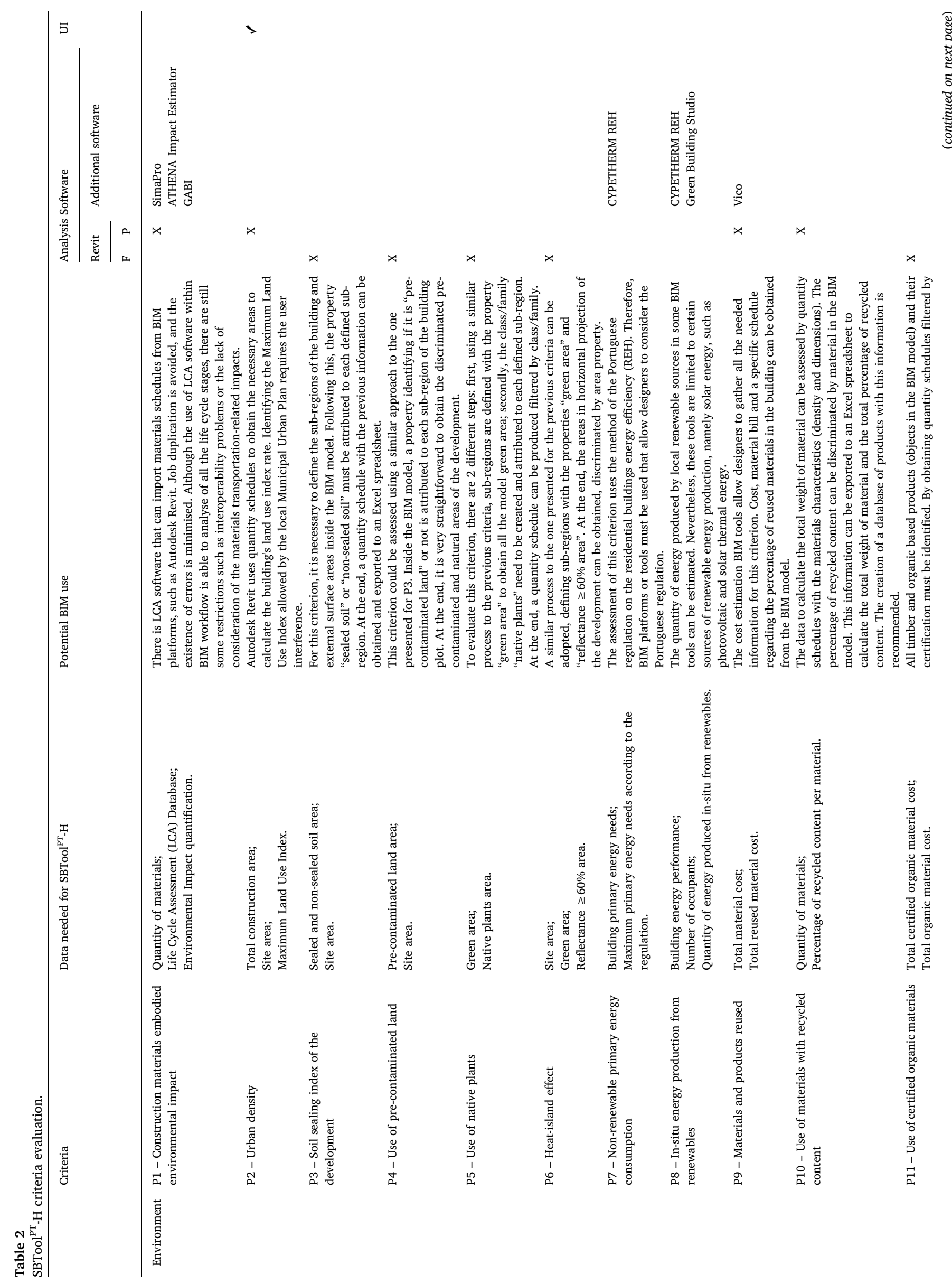




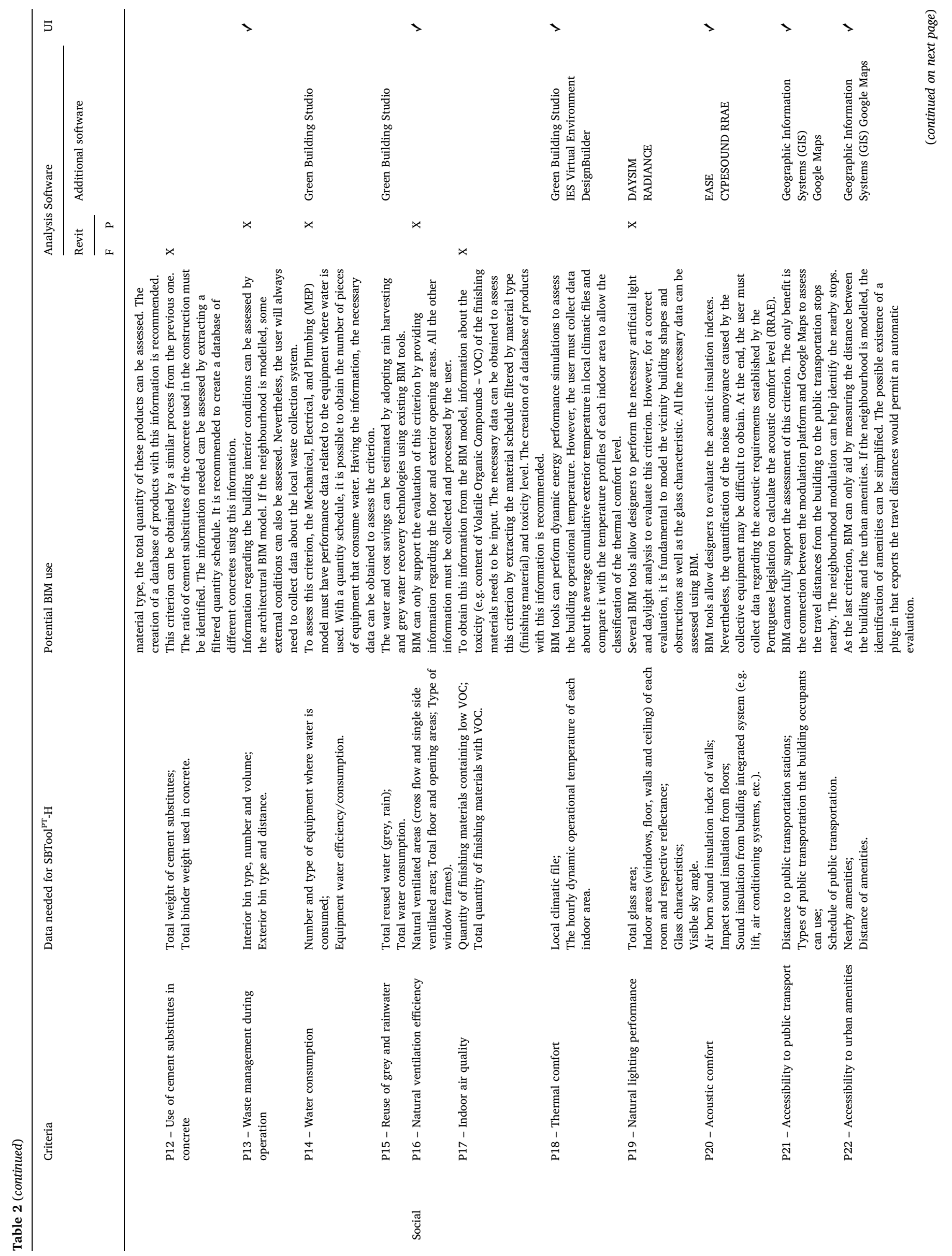


Based on the previous analysis, Fig. 3 presents a possible organisation for the SBTool ${ }^{\mathrm{BIM}}$ framework. Fig. 3 presents the different stages of the assessment process for the SBTool ${ }^{\mathrm{PT}}-\mathrm{H}$, the information flow, as well as the additional software needed when a BIM-based end-user application is used.

First, it is necessary to collect all the data for the BIM model. Thus, the model will have the necessary information which enables stakeholders to compare the performance and sustainability level of different design scenarios. It is recommended that stakeholders collect and define all the needed information and guidelines for the project before the modulation stage. By doing so, this phase will be developed smoothly and faster since they will only focus on performing the building assessment.

The second phase is the model creation in a BIM platform, e.g. Autodesk Revit. It includes all the models (Site, Architectural, Structural, and MEP) together with the attributes of the different areas, materials and building elements used.

The third phase is the sustainability criteria assessment (except for the ones that require the neighbourhood modulation). The interoperability between these platforms and tools can be performed using the following data exchange formats: Industry Foundation Classes (IFC), Green Building XML (gbXML) and Autodesk Revit direct links. Since these data exchange formats are not fully developed yet, some interoperability problems may occur, and information may not be completely transmitted from one model to another.

To assess the remaining criteria, the fourth phase is the neighbourhood modulation. Using a BIM/GIS software will allow designers to create building shapes and typologies with some specific attributes and details.

When all the data needed to perform the building sustainability assessment is collected, it is necessary to define a method to aggregate the results from different software. This will be the main challenge in this phase. Since it is necessary to use several different software, aggregating and making the results compatible may be a time-consuming process.

Finally, it is necessary to adapt the SBTool ${ }^{\mathrm{PT}}-\mathrm{H}$ spreadsheet to be connected with a specific spreadsheet that contains the data from the BIM platforms and tools in order to automatically fill the required information to assess the SBTool ${ }^{\mathrm{PT}}-\mathrm{H}$ criteria. With the conceptual framework for the BIM-based end-user application and with all the necessary software identified, it is possible to start streamlining the core of the BIM-based end-user application - SBTool ${ }^{\mathrm{BIM}}$.

This BIM-based end-user application aims to simplify and speed up the $\mathrm{SBTool}^{\mathrm{PT}}-\mathrm{H}$ assessment process by automating the assessment procedure. At the same time, it will promote the introduction of sustainable measures, as well as support designer's decision making during the project stage. Thus, the typical time-consuming process of $\mathrm{SBTool}^{\mathrm{PT}}-\mathrm{H}$ assessment will be reduced, encouraging designers to optimise the sustainability of their projects.

The SBTool ${ }^{\mathrm{BIM}}$ will be connected to Autodesk Revit and will be developed using the Autodesk Revit API. The SBTool ${ }^{\text {BIM }}$ application will be able to extract specific data from the BIM model to assess, whenever possible, the SBTool ${ }^{\mathrm{PT}}-\mathrm{H}$ criteria. Based on the research, the SBTool ${ }^{\mathrm{BI}}$ will be divided into three different phases, according to the required assessment procedure for the different sustainability criteria, as presented in Table 3. These phases were based on the analysis made in Table 2, where the type of information and the necessary software to assess each sustainability criteria were identified. Phase one gathers all criteria that can be assessed directly from the data that is possible to extract from the virtual model in the BIM platform. Those criteria that need additional and specific external BIM tools to access certain qualitative and quantitative parameters to be used in the BSA method $\mathrm{SBTool}^{\mathrm{PT}}-\mathrm{H}$ are included in the second phase. Finally, those criteria which need information from outside the building boundaries are organised in phase three.

SBTool $^{\mathrm{BIM}}$ can be applied individually in each of the three assessment phases. By doing this the project sustainability level from the 


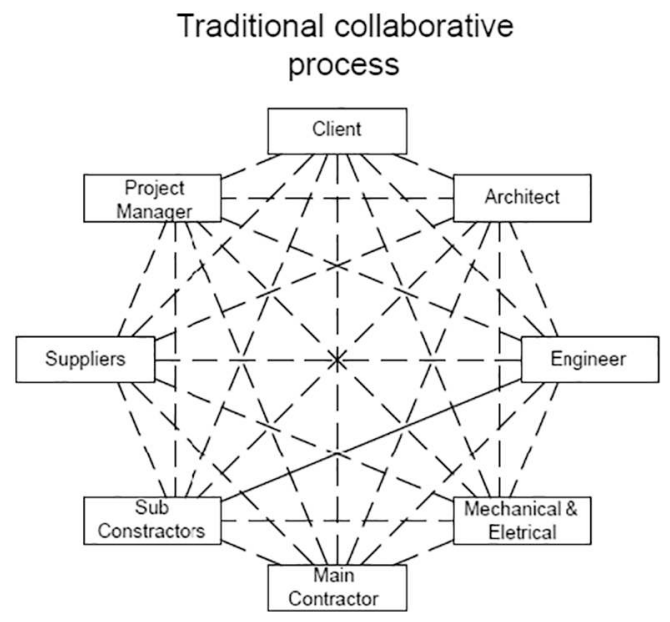

Fig. 1. Traditional approach vs a BIM approach, adapted from [19].
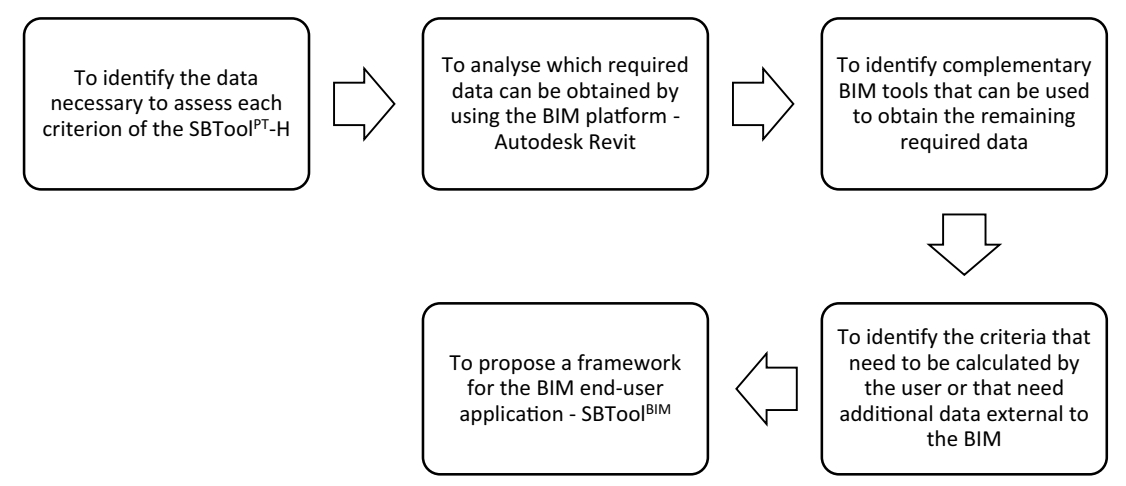

Fig. 2. Research procedure.

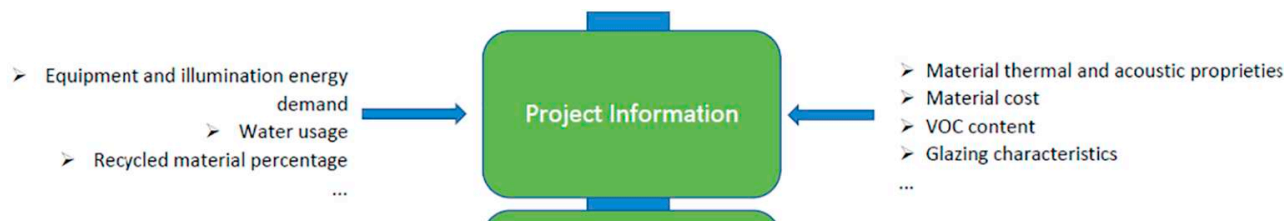

The case of SBTool ${ }^{\text {PT }}$-H

P1 - SimaPro or ATHENA or GAEI ( $\bullet$

P2 - Revit $(\bullet)$

P3 - Revit $(\bullet)$

P4 - Revit $(\bullet)$

P5-Revit ( $\bullet$

P6 - Revit $(\bullet)$

P7 - CYPETHERM REH $(\bullet)$

P8 - CYPETHERM REH \& Green Building Studio $(\bullet)$

$P 9-$ Vico Office $(\Delta)$

P10 - Revit $(\Delta)$

P11 - Revit $(\bullet)$

P12 - Revit $(\bullet)$

P13 - Revit $(\Delta)$

P14 - Green Building Studio $(\bullet)$

P15 - Green Building Studio $(\bullet)$

P16 - Revit $(\Delta)$

P17 - Revit $(\bullet)$

P18 - Green Building Studio or IES Virtual

Environment or DesignBuilder $(\Delta)$

P19 - DAYSIM or Radiance $(\bullet)$

P2O - CYPESOUND RRAE $(\Delta)$

P24 - Vico Office ( $\triangle$ )

P25 - Green Building Studio or DesignBuilder or CYPETHERM REH $(\Delta)$

Fully evaluate $(\bullet)$ Partially evaluate $(\Delta)$

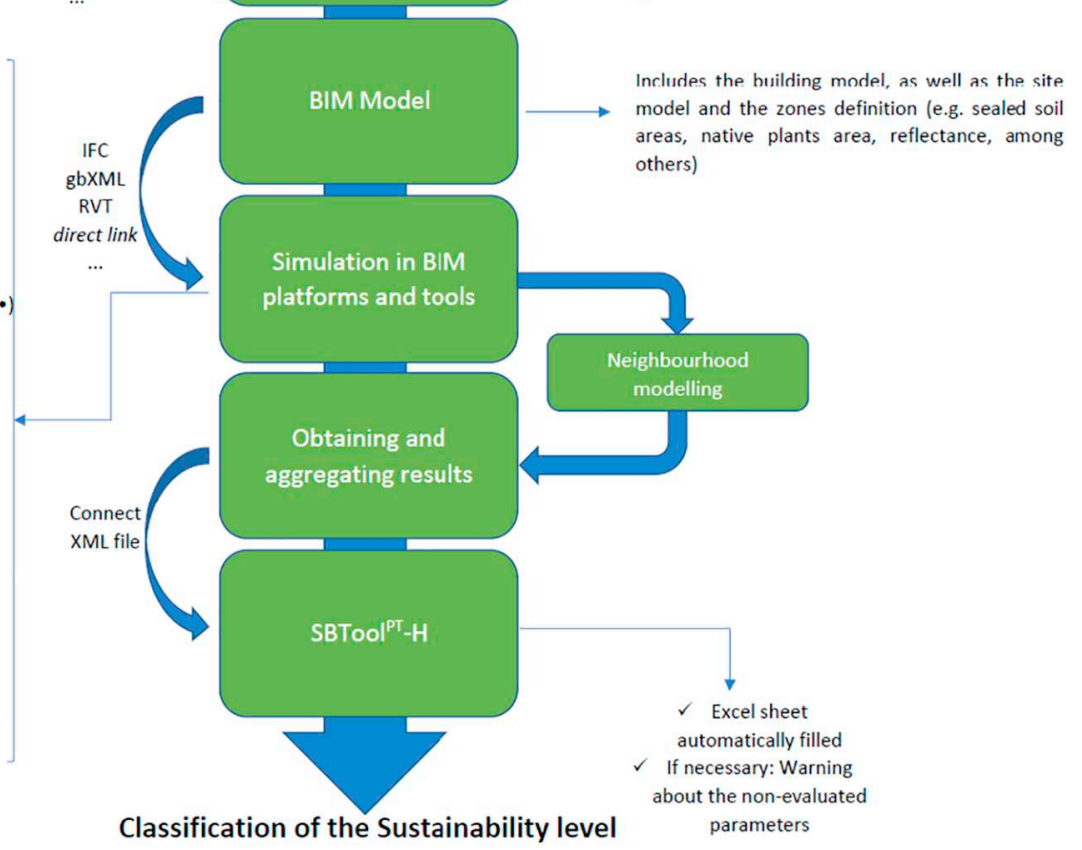

Fig. 3. Basis for SBTool ${ }^{\mathrm{BIM}}$ organisation framework. 
Table 3

Assessment phases for the SBTool ${ }^{\mathrm{BIM}}$ framework according to the assessment procedure.

\begin{tabular}{|c|c|c|c|c|}
\hline Phase & Description & Criteria assessed & $\begin{array}{l}\text { Fully or Partially } \\
\text { assessed }\end{array}$ & UI \\
\hline \multirow[t]{11}{*}{1} & \multirow{11}{*}{$\begin{array}{l}\text { The SBTool }{ }^{\mathrm{BIM}} \text { will only gather information from the Autodesk Revit BIM model, as dimensions and quantities. } \\
\text { The user must endow the BIM model with some specific information, such as VOC content, green area, recycled content, } \\
\text { etc. The data will be produced, directly and only in Autodesk Revit, by quantity schedules. In this assessment phase, the } \\
\text { user does not need to export or import any type of file or perform any kind of analysis. The BIM model must have } \\
\text { information regarding architecture, structural and Mechanical-Electrical-Pluming (MEP) disciplines. } \\
\text { Criterion P23 cannot be directly supported by BIM. However, SBTool }{ }^{\text {BIM }} \text { will be prepared to ask the user to introduce } \\
\text { some information regarding the existence and content of the building user manual. }\end{array}$} & P2 & Fully & $\checkmark$ \\
\hline & & P3 & Fully & \\
\hline & & P4 & Fully & \\
\hline & & P5 & Fully & \\
\hline & & P6 & Fully & \\
\hline & & $\mathrm{P} 10$ & Partially & \\
\hline & & P11 & Fully & \\
\hline & & $\mathrm{P} 12$ & Fully & \\
\hline & & P16 & Partially & $\checkmark$ \\
\hline & & P17 & Fully & \\
\hline & & P23 & - & $\checkmark$ \\
\hline \multirow[t]{10}{*}{2} & \multirow{10}{*}{$\begin{array}{l}\text { This assessment phase consists of gathering specific information produced by external BIM analysis tools (such as } \\
\text { thermal analysis, daylight analysis, LCA, water consumption, costs...). The way that data will be gathered depends on } \\
\text { the analysis procedure: if Autodesk Revit direct link is used, SBTool }{ }^{\mathrm{BI}} \text { will automatically filter the necessary data for the } \\
\text { assessment when the analysis is made. If Autodesk Revit direct links are not available, SBTool }{ }^{\mathrm{BIM}} \text { will gather the data } \\
\text { when the IFC or gbXML file (with the analysis data) is uploaded to Autodesk Revit. }\end{array}$} & $\mathrm{P} 1$ & Fully & \\
\hline & & P7 & Fully & \\
\hline & & P8 & Fully & \\
\hline & & P9 & Partially & \\
\hline & & $\mathrm{P} 14$ & Fully & \\
\hline & & P15 & Fully & \\
\hline & & P18 & Partially & $\checkmark$ \\
\hline & & P20 & Partially & $\checkmark$ \\
\hline & & P24 & Partially & $\checkmark$ \\
\hline & & P25 & Partially & $\checkmark$ \\
\hline \multirow[t]{4}{*}{3} & \multirow{4}{*}{$\begin{array}{l}\text { The last assessment phase can be better applied when the neighbourhood is modelled. If the user has the necessary } \\
\text { information, by using BIM-GIS software and Google Maps, some data for the assessment can be collected. Despite that, } \\
\text { BIM cannot fully evaluate all these criteria, but the provided information can save the designer's time compared with the } \\
\text { manual assessment procedures. }\end{array}$} & $\mathrm{P} 13$ & Partially & $\checkmark$ \\
\hline & & P19 & Fully & \\
\hline & & P21 & Partially & $\checkmark$ \\
\hline & & P22 & Fully & $\checkmark$ \\
\hline
\end{tabular}

beginning of the design will be improved. Before the assessment, the SBTool $^{\mathrm{BIM}}$ will also ask the user for some input data, namely, the "external information", such as regulatory data or energy and water fares.

After the SBTool ${ }^{\mathrm{BIM}}$ has all the information for each assessment phase, it will perform the calculations needed or simply extract data for a new Excel Spreadsheet that will be linked to the original SBTool ${ }^{\mathrm{PT}}-\mathrm{H}$ Excel spreadsheet, following the flow presented in Figs. 4, 5 and 6, for each assessment phase respectively. Thus, whenever the information is available, the $\mathrm{SBTool}^{\mathrm{PT}}$-H spreadsheet will be automatically filled and a sustainability score will be calculated. Besides the result being presented in the $\mathrm{SBTool}^{\mathrm{PT}}$-H worksheet, the aim is that the sustainability score can also be displayed in Autodesk Revit, so that the user can rapidly assess and improve the sustainability level of the project. When a possible error occurs, or missing information is required, SBTool ${ }^{\mathrm{BIM}}$ will display a warning with the error report.

In the first assessment phase (Fig. 4), the Autodesk Revit scheduling function will be used to extract quantitative information from the virtual model. The Autodesk Revit scheduling function provides an overview of different sources of information and quantifies the building materials and elements [2]. By detailing the information of building materials and components, all the dimensional and quantities data for the evaluation of the SBTool ${ }^{\mathrm{PT}}-\mathrm{H}$ criteria P2, P3, P4, P5, P6, P10, P11, $\mathrm{P} 12, \mathrm{P} 16$, and $\mathrm{P} 17$ can be assessed. The importance of providing the model and its objects with a certain level of information should be highlighted - such as material and site area characteristics (as listed in the "Extra data" in Fig. 4) - in order to extract and perform a correct quantity filtration, both for areas and materials. Otherwise, most of the data, such as native plants area, sealed soil area or the VOC content will be impossible to assess.

As a general example for this phase, Fig. 7 presents the assessment procedure for criterion P5 - Use of native plants from category C2 - Land use and biodiversity. As stated, it is essential to detail the virtual model,

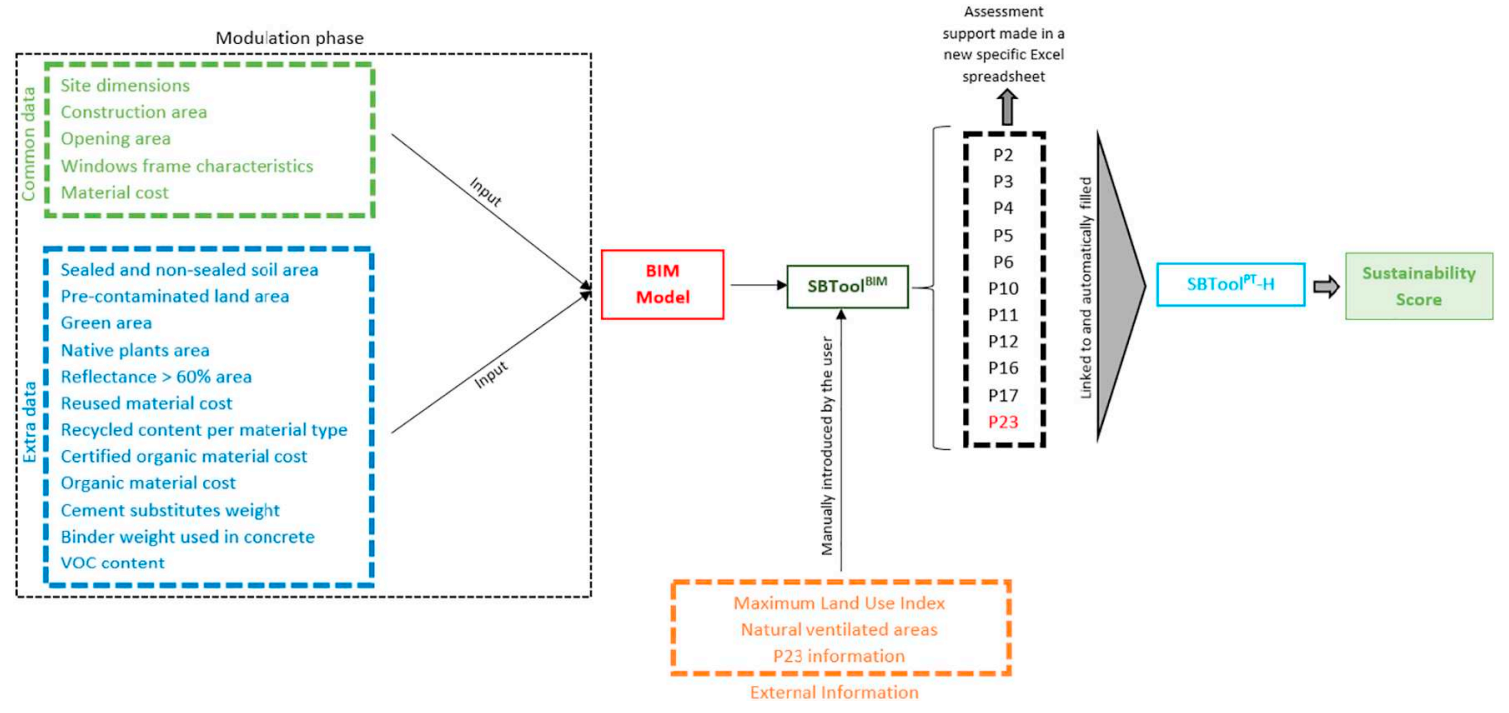

Fig. 4. Information flow - SBToolBIM - Phase 1 . 


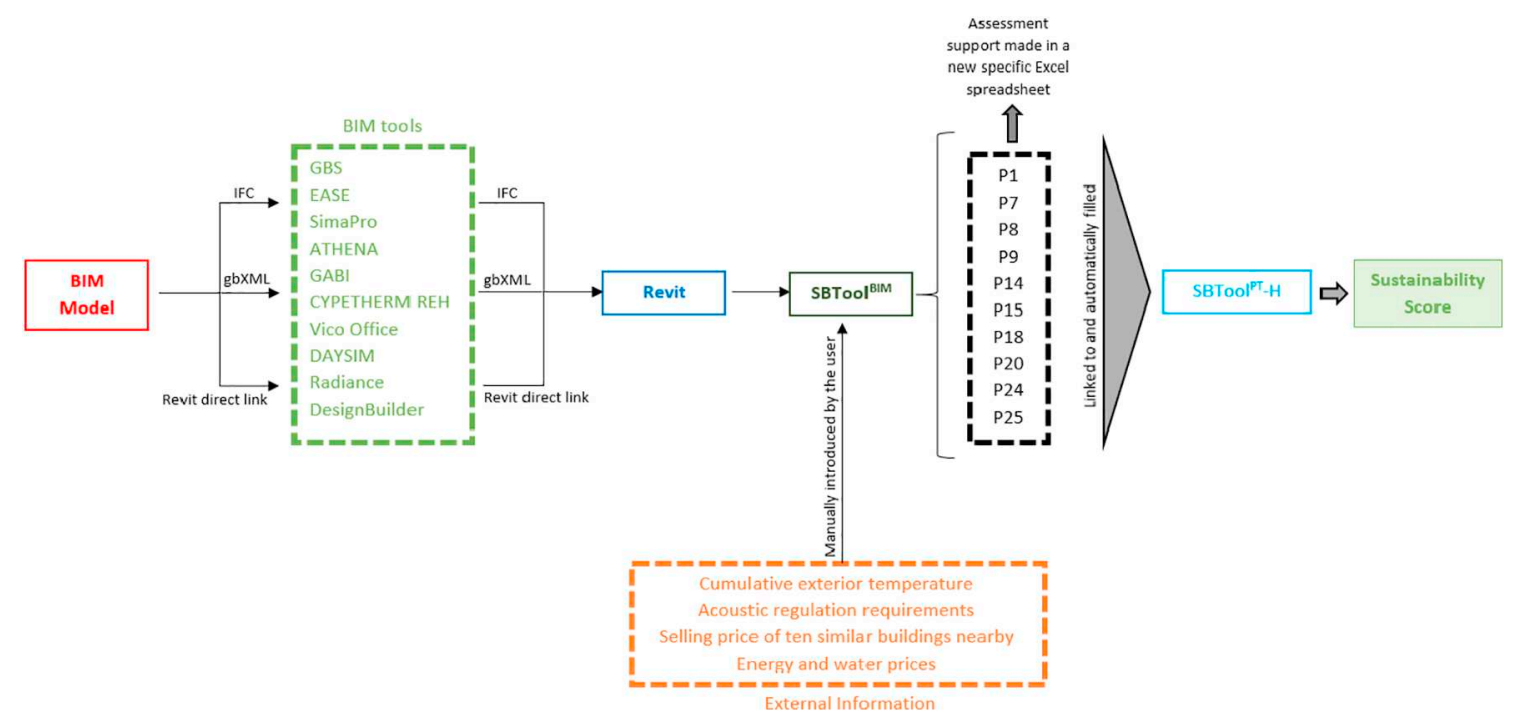

Fig. 5. Information flow - SBToolBIM - Phase 2.

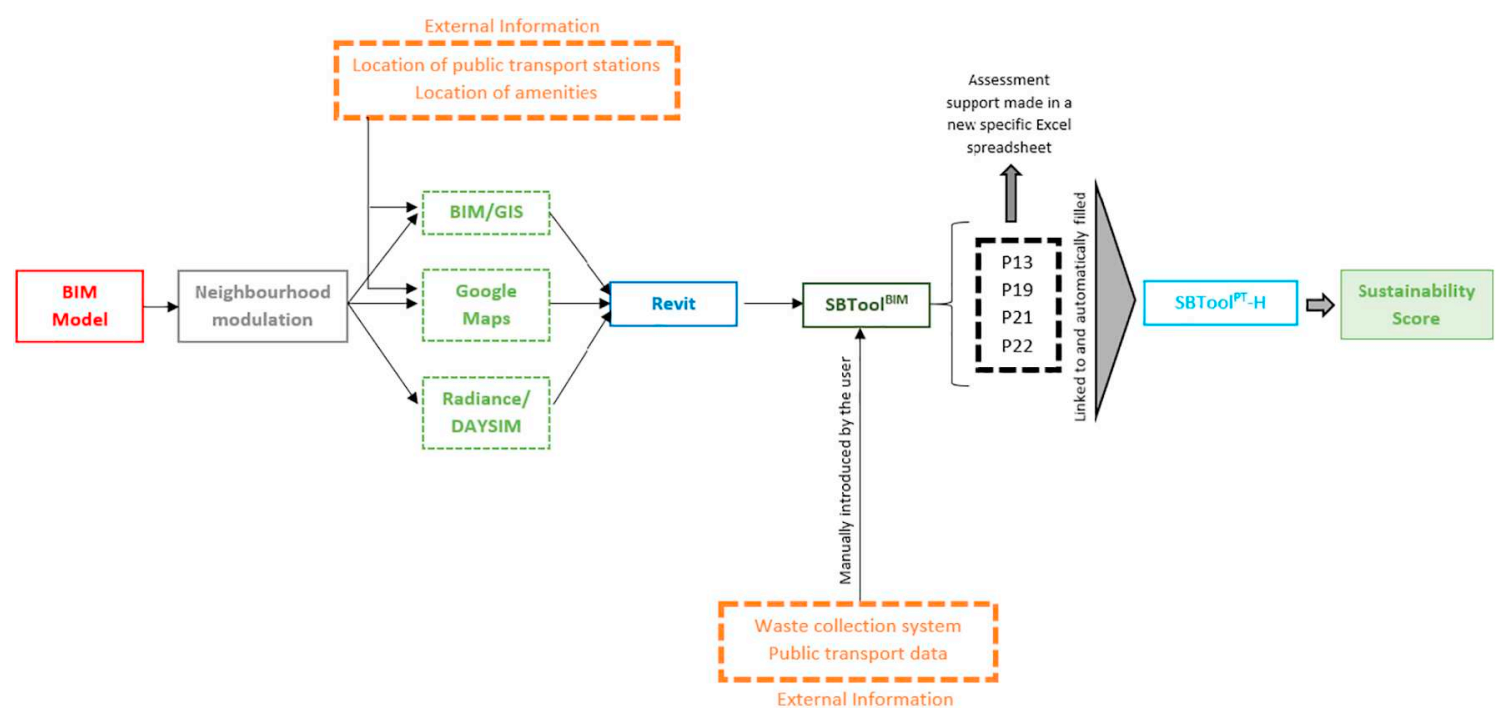

Fig. 6. Information flow - SBToolBIM - Phase 3 .

in Autodesk Revit, with the required information to evaluate the performance at criterion P5, which is related to the percentage of the building site green area occupied by native plants. Then, by using the Autodesk Revit schedule function, a quantity schedule filter by region and native plants can be obtained with the building's total green area and number/area of native plants. Objects representing native plants should be created, detailed and stored in the Autodesk Revit library or the native plant regions should be defined. This schedule is then extracted to a new spreadsheet, which in turn is linked to the SBTool ${ }^{\mathrm{PT}}-\mathrm{H}$ spreadsheet and an assessment for criterion P5 can be reached. As the virtual model objects can have different types of information, several criteria can be easily and simultaneously assessed by selecting proper filters in the schedule function. Other criterion such as $P 2-U r b a n$ density (Fig. 7) can easily be assessed, as it only requires extracting an area schedule filtered by level. In the case of P2, the user must also manually insert the Maximum Land Use Index defined by the local municipal regulation into the $\mathrm{SBTool}^{\mathrm{PT}}$-H spreadsheet.

The second assessment phase (Fig. 5) consists of gathering qualitative and quantitative information from IFC and gbXML sources and Autodesk Revit direct links, which have been used in specific BIM tools (for sustainability analysis purposes, such as energy performance simulation or acoustic analysis). The SBTool ${ }^{\mathrm{BIM}}$ will automatically gather information from Autodesk Revit direct links or when the IFC or gbXML source files are uploaded again in Autodesk Revit. In this phase, the following SBTool ${ }^{\mathrm{PT}}$-H criteria: P1, P7, P8, P9, P14, P15, P18, P20, P24, and P25 can be assessed directly or indirectly.

Concerning the use of BIM tools in this assessment phase, the user will need to input some information directly into those BIM tools (e.g. utility prices or PV panel characteristics), as well as prepare the BIM model (in Autodesk Revit) to perform the intended analysis. For instance, to perform thermal analysis, the user must define the energy settings in Autodesk Revit before exporting the file. The criteria assessment in this phase is expected to be a time-consuming process, as different analysis from several BIM tools are required. Besides the fact that the user needs to prepare the BIM model for the BIM tool simulation, the analysis must be performed individually and sequentially, tool by tool. These needs reinforce the fact that BIM software should include more sustainability issues, in order to reduce the number of BIM tools that are necessary to assess a few sustainability criteria from just one BSA method. Further developments are still necessary to reduce the necessary time and tasks for this assessment phase procedure.

As an assessment example, the evaluation procedure for category C3 - Energy Efficiency (which includes criteria P7 - Non-renewable primary energy consumption and $P 8$ - In-situ energy production from renewables) is 


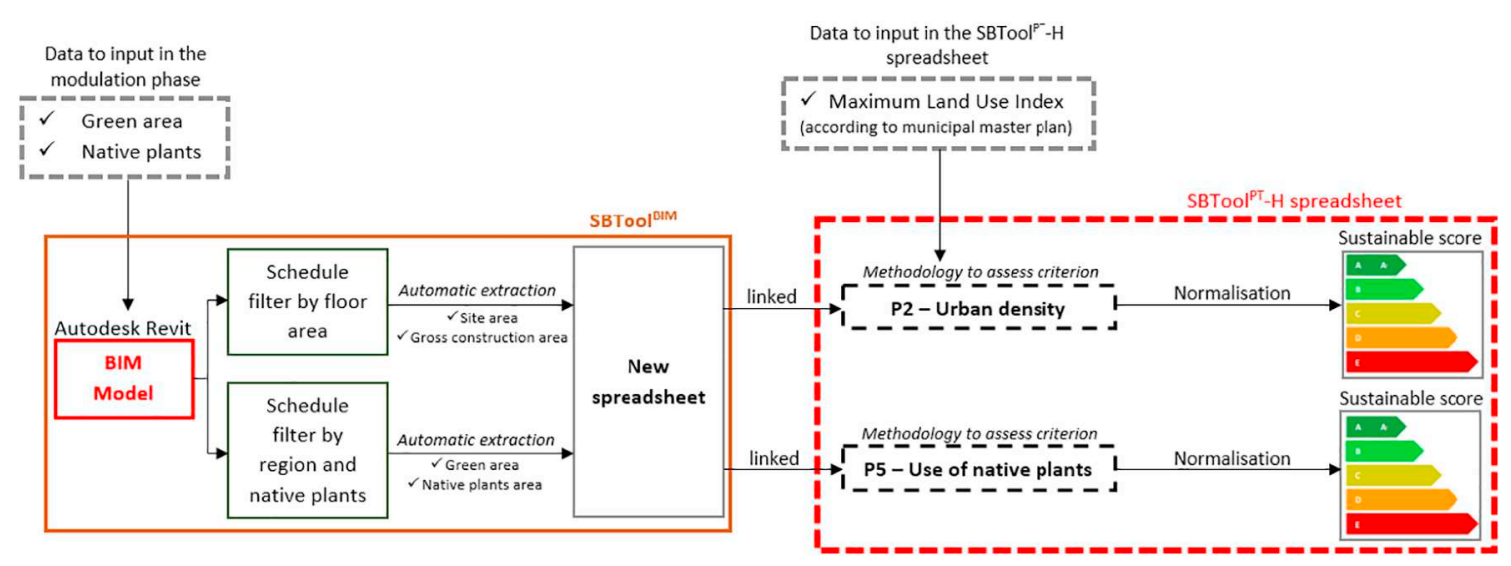

Fig. 7. Assessment of SBTool ${ }^{\mathrm{PT}}-\mathrm{H}$ criteria P2 and P5.

presented in Fig. 8. By exporting the virtual model IFC file from Autodesk Revit to an additional BIM tool for energy analysis - CYPETHERM REH - the heating, cooling, domestic hot water (DHW) and primary energy needs can be assessed, according to the Portuguese regulation (as well as the regulation limit values). In this case, before the model simulation in CYPETHERM REH, the renewable energy production needs to be known, which must be done in Autodesk Green Building Studio. Having obtained this data, together with the building area and the number of occupants (extracted from the virtual model), all the required information to assess the criteria P7 and P8 is available.

The third assessment phase (Fig. 6) focuses on the evaluation of the building surrounding environment and neighbourhood quality, to support the assessment of criteria P13, P19, P21, and P22. Most of these criteria will require the knowledge of some necessary information, for example, the distance to the recycling bins, the distances between the building and nearby amenities and public transport stations or the public transport frequency. Google Maps Revit plug-in is expected to be used to evaluate distances (in meters and in time). To do that, the user will need to define the building location and introduce the location of public transport stations and urban amenities.

Fig. 9 presents an assessment example for this phase, focusing on criteria P21 - Accessibility to public transport and P22 - Accessibility to urban amenities from category C7 - Accessibilities. To find out the distances and travel times between the building and nearby transport stations and amenities, a similar process to the one developed by Jalaei and Jrade [44] will be used. The SBTool ${ }^{\text {BIM }}$ will be linked to Google Maps and by introducing the destination addresses (e.g. postal codes), the application will connect with Google Maps and present the distance (in meters) and travel time (in minutes) from the building. This data will support the assessment of the selected criteria.

As presented earlier, some of the criteria cannot be fully assessed by using BIM. Whenever this happens, the $\mathrm{SBTool}^{\mathrm{BIM}}$ will fill in the $\mathrm{SBTool}^{\mathrm{PT}}$-H worksheet with the available data and alert the user, indicating which criteria were not assessed and what information is still missing. Then, the user must collect the missing data and make the necessary calculations to finalise the criteria assessment. Nevertheless, it is expected that the assessment of all the sustainability criteria will be improved somehow, in terms of time, by using SBTool ${ }^{\mathrm{BIM}}$.

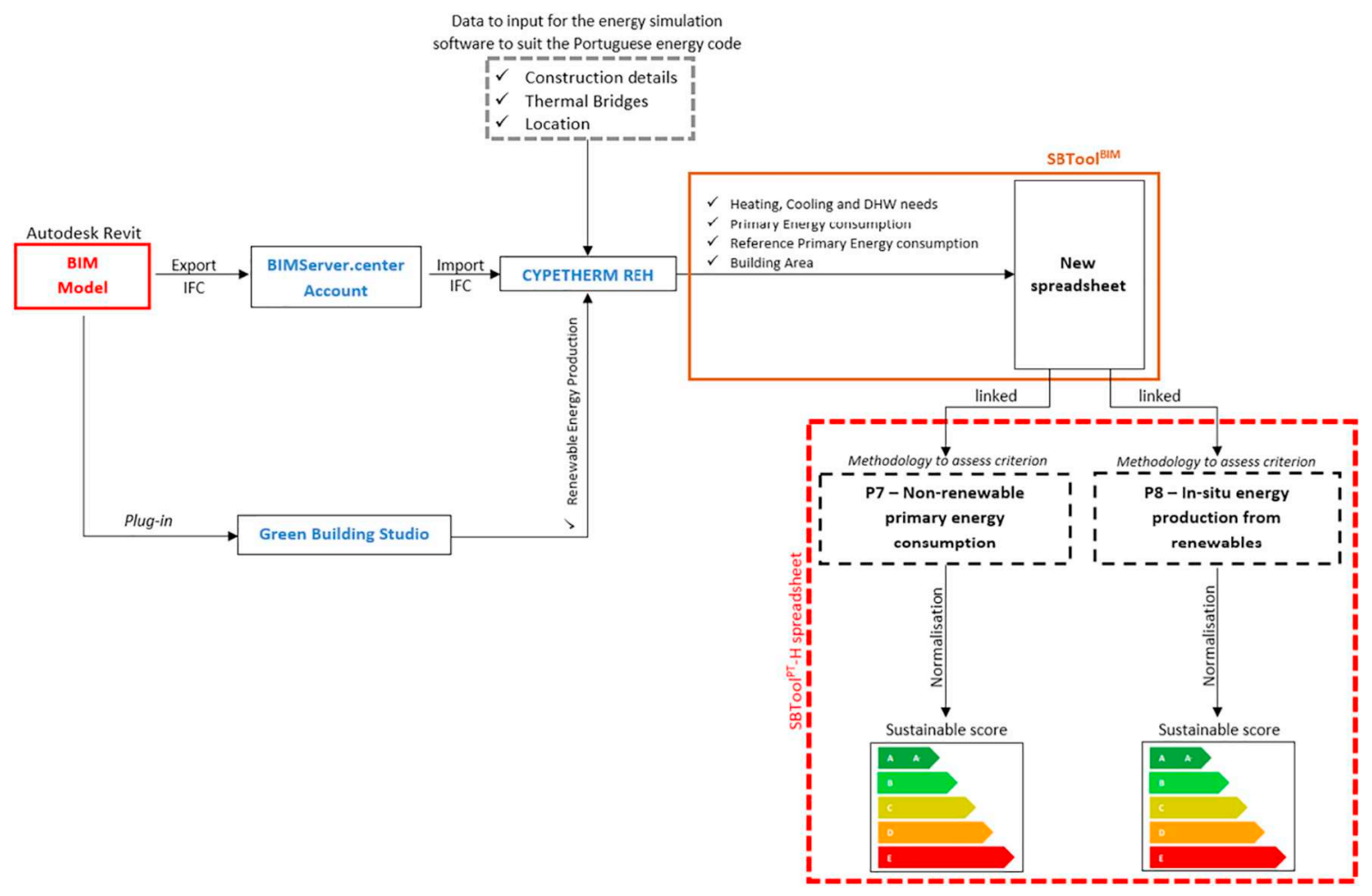

Fig. 8. Assessment of $\mathrm{SBTool}^{\mathrm{PT}}-\mathrm{H}$ criteria P7 and P8. 


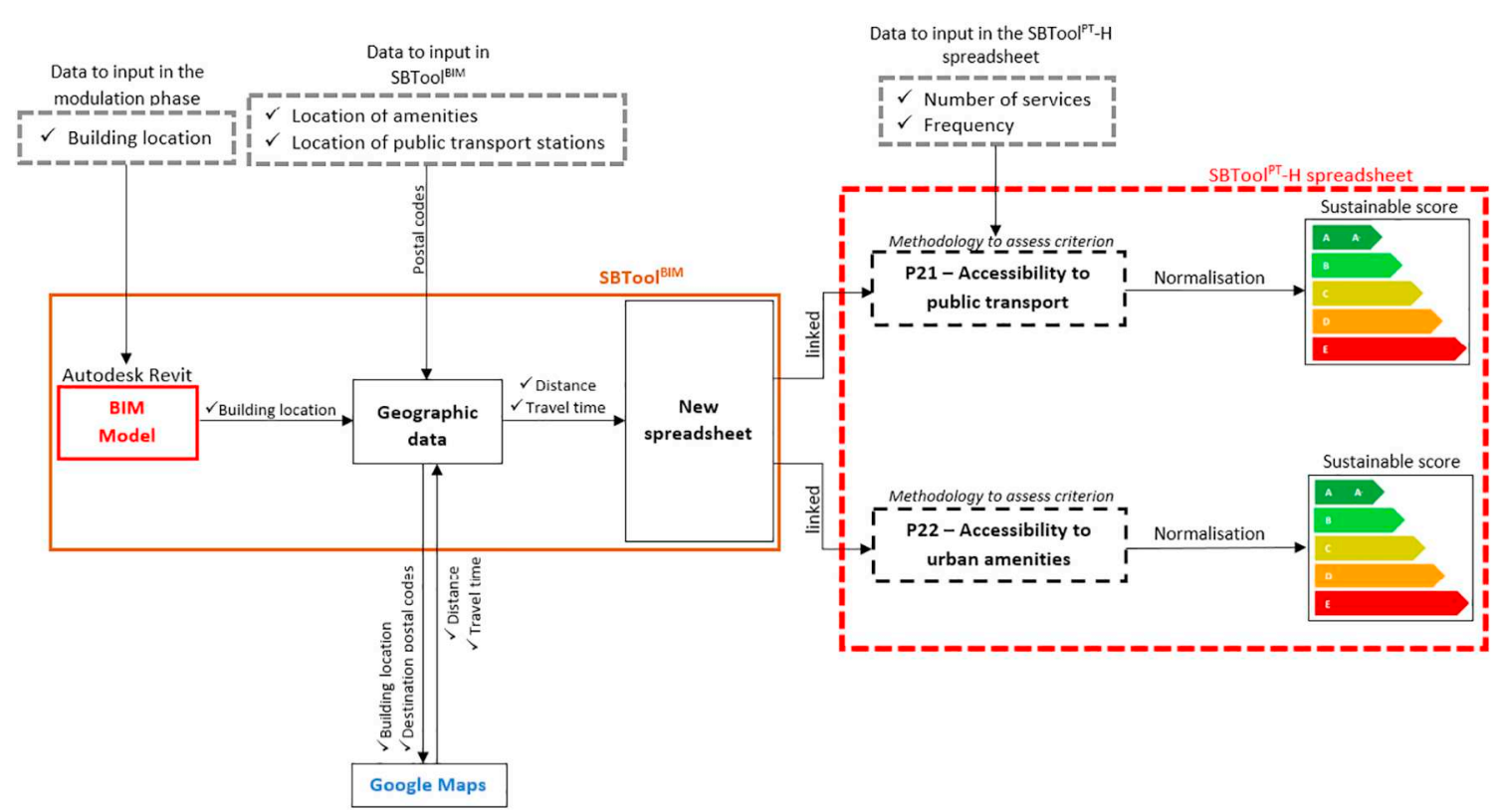

Fig. 9. Assessment of $\mathrm{SBTool}^{\mathrm{PT}}-\mathrm{H}$ criteria $\mathrm{P} 21$ and $\mathrm{P} 22$.

Regarding the stage at which to perform the sustainability assessment, it should be done as soon as possible during the project design phases, so designers can start making changes to optimise the building performance from the first choices. However, as different criteria must be evaluated in different project phases with different procedures, a comprehensive sustainability assessment will only be possible to obtain at a later stage of the process.

\section{Conclusions}

The use of the BIM method in the AEC industry may be an essential path to optimise building performance and reduce the environmental impacts of the industry in the future. Given the demand for better and sustainable buildings, it is important to create ways to integrate and automate the Building Sustainability Assessment (BSA) methods within the BIM context. Therefore, project teams will be able to identify and compare different sustainable design scenarios at an early stage of the project, without spending too much time, money and other resources.

Despite the existing studies in some BSA methods, a technique to use BIM in BSA has not yet been established. According to the results presented in this paper, BIM documentation can be used to directly or indirectly evaluate most of the SBTool ${ }^{\mathrm{PT}}$-H sustainability criteria in an automatic and faster way when compared to the traditional processes. The results have shown that $8 \mathrm{SBTool}^{\mathrm{PT}}$-H criteria can be fully assessed and 3 partially assessed only by using Autodesk Revit. These are mainly concerning dimensional and quantity criteria and are obtained by using the scheduling function that is one of the main advantages of the BIM to simplify the assessment by using this BSA method. It has also been found that for 13 criteria additional software is still necessary to provide all or part of the required data for the assessment.

As BSA methods are based on a set of different sustainability criteria, different BIM tools are still needed to assess the required information, which can be a barrier to using BIM to assess the different sustainability criteria. Actual BIM software is not adapted to assess many sustainability criteria. Thus, the need for a plug-in that includes the necessary software and aggregates all the results from BIM software arises. However, as different BSA methods have different sustainability criteria, a specific plug-in oriented to each BSA method is necessary to optimise and automate the assessment process.

Overall, it was found that even though BIM is still not oriented to building sustainability, it has great potential. Both BIM software and plug-ins still need improvements and further developments in this field in order to be suitable to use for BSA purposes. The use of fewer BIM software to evaluate one BSA method and an easier way to assess many sustainability criteria at once are still necessary to improve time-efficiency. These conclusions are in line with similar studies for other BSA methods, presented in the state-of-art analysis, which pointed out the lack of data provided by the BIM platforms and tools to be used in the sustainability assessments.

With the development of SBTool ${ }^{\mathrm{BIM}}$, major contributions are expected to improve the sustainability level of the buildings. As this is a BIM-based method, both BIM integration benefits and the benefits of using BSA methods will be achievable for projects and companies. As BSA is typically made in later stages and apart from the conventional design phases, project changes to improve buildings sustainability are expensive and usually unfeasible. By integrating BSA into this kind of approach, the sustainability assessment will be articulated with all the other project disciplines, improving information-sharing among stakeholders. Designers will be able to assess their buildings sustainability from the early stages of the project. By supporting designer's decisionmaking, sustainable measures can be introduced and compared with lower costs and resources consumption in a shorter period of time.

Nevertheless, some restrictions can be observed in the proposed framework for the SBTool ${ }^{\mathrm{BIM}}$ that need to be overcome in order to automate the full evaluation process. Some of these restrictions are the neighbourhood modulation and the technique to aggregate the results from several different software, which may not be compatible among them.

It must be noted that maximum benefits can only be achieved when the construction companies have the knowledge or have integrated BIM in their processes. Otherwise, there will be an adaptation period, where the benefits will not be so noticeable.

\section{References}

[1] R.J. Cole, Building environmental assessment methods: redefining intentions and roles, Building Research \& Information. 33 (2005) 455-467, https://doi.org/10. 1080/09613210500219063.

[2] J.K.-W. Wong, K.-L. Kuan, Implementing 'BEAM Plus' for BIM-based sustainability analysis, Autom. Constr. 44 (2014) 163-175, https://doi.org/10.1016/J.AUTCON. 2014.04.003.

[3] Y.H. Dong, S.T. Ng, A life cycle assessment model for evaluating the environmental impacts of building construction in Hong Kong, Build. Environ. 89 (2015) 183-191, https://doi.org/10.1016/J.BUILDENV.2015.02.020. 
[4] T. Jia Wen, H. Chin Siong, Z.Z. Noor, Assessment of embodied energy and global warming potential of building construction using life cycle analysis approach: case studies of residential buildings in Iskandar Malaysia, Energy and Buildings. 93 (2015) 295-302, https://doi.org/10.1016/J.ENBUILD.2014.12.002.

[5] Y. Li, X. Chen, X. Wang, Y. Xu, P.-H. Chen, A review of studies on green building assessment methods by comparative analysis, Energy and Buildings. 146 (2017) 152-159, https://doi.org/10.1016/J.ENBUILD.2017.04.076.

[6] C. Araújo, M. Almeida, L. Bragança, Analysis of some Portuguese thermal regulation parameters, Energy and Buildings. 58 (2013) 141-150, https://doi.org/10.1016/J. ENBUILD.2012.11.024.

[7] T.F. da C.T. Lopes, Reabilitação sustentável de edifícios de habitação (Sustainable rehabilitation of residential buildings), Faculdade de Ciências e Tecnologia, 2010, https://run.unl.pt/handle/10362/4138, Accessed date: 13 November 2018.

[8] G.H. Brundtland, Our Common Future: Report of the World Commission on Environment and Development, Oslo (1987), https://doi.org/10.1080/ 07488008808408783.

[9] R.M.C. Horta, Construção sustentável de edifícios de balanço energético quase zero (Sustainable construction of nearly zero-energy buildings), Faculdade de Ciências e Tecnologia https://run.unl.pt/handle/10362/9143, (2012) , Accessed date: 13 November 2018

[10] L.P.S. Cardoso, Reabilitação sustentável de edifícios Anteriores a 1951 (Sustainable Refurbishment of Buildings Built before 1951), Universidade do Minho, 2013, http://repositorium.sdum.uminho.pt/handle/1822/30877, Accessed date: 13 November 2018

[11] C.J. Kibert, Establishing principles and a model for sustainable construction, Sustainable Construction: Proceedings of the First International Conference of CIB TG 16, November 6-9, Center for Construction and Environment, M.E. Rinker Sr. School of Building Construction, College of Architecure, University of Florida, Tampa, Florida, 19949780964388611 , p. 888 ISBN.

[12] R. Mateus, L. Bragança, Sustainability assessment and rating of buildings: developing the methodology SBToolPT-H, Build. Environ. 46 (2011) 1962-1971, https://doi.org/10.1016/J.BUILDENV.2011.04.023.

[13] A. Haapio, P. Viitaniemi, A critical review of building environmental assessment tools, Environ. Impact Assess. Rev. 28 (2008) 469-482, https://doi.org/10.1016/J. EIAR.2008.01.002

[14] J.K.W. Wong, J. Zhou, Enhancing environmental sustainability over building life cycles through green BIM: a review, Autom. Constr. 57 (2015) 156-165, https:// doi.org/10.1016/J.AUTCON.2015.06.003.

[15] S.N. Kamaruzzaman, H. Salleh, E.C. Weng Lou, R. Edwards, P.F. Wong, Assessment schemes for sustainability design through BIM: lessons learnt, in: S.N.B. Kamaruzzaman, A.S.B. Ali, N.F.B. Azmi, S.J.L. Chua (Eds.), MATEC Web of Conferences, The 4th International Building Control Conference, EDP Sciences, Kuala Lumpur, Malaysia, 2016, p. 00080, , https://doi.org/10.1051/matecconf/ 20166600080.

[16] D. Bryde, M. Broquetas, J.M. Volm, The project benefits of building information modelling (BIM), Int. J. Proj. Manag. 31 (2013) 971-980, https://doi.org/10.1016/ J.IJPROMAN.2012.12.001.

[17] B. Succar, Building information modelling framework: a research and delivery foundation for industry stakeholders, Autom. Constr. 18 (2009) 357-375, https:// doi.org/10.1016/J.AUTCON.2008.10.003.

[18] C.M. Eastman, BIM Handbook: A Guide to Building Information Modeling for Owners, Managers, Designers, Engineers and Contractors, John Wiley \& Sons, 9780470541371, 2011 ISBN.

[19] P. Wilkinson, BIM: An Overview, https://pt.slideshare.net/EEPaul/cimcig-bimconference, (2012), Accessed date: 13 November 2018.

[20] S. Azhar, Building information modeling (BIM): trends, benefits, risks, and challenges for the AEC industry, Leadersh. Manag. Eng. 11 (2011) 241-252, https://doi. org/10.1061/(ASCE)LM.1943-5630.0000127.

[21] S. Azhar, J. Brown, BIM for sustainability analyses, Int. J. Constr. Educ. Res. 5 (2009) 276-292, https://doi.org/10.1080/15578770903355657.

[22] K. Ku, M. Taiebat, BIM experiences and expectations: the Constructors' perspective, Int. J. Constr. Educ. Res. 7 (2011) 175-197, https://doi.org/10.1080/15578771. 2010.544155

[23] R. Eadie, M. Browne, H. Odeyinka, C. McKeown, S. McNiff, BIM implementation throughout the UK construction project lifecycle: an analysis, Autom. Constr. 36 (2013) 145-151, https://doi.org/10.1016/J.AUTCON.2013.09.001.
[24] I. Motawa, K. Carter, Sustainable BIM-based evaluation of buildings, Procedia Social and Behavioral Sciences. 74 (2013) 419-428, https://doi.org/10.1016/J. SBSPRO.2013.03.015.

[25] M. Solla, L.H. Ismail, R. Yunus, Investigation on the potential of integrating BIM into green building assessment tools, ARPN Journal of Engineering and Applied Sciences. 11 (2016) 2412-2418, https://doi.org/10.13140/RG.2.1.4114.0881.

[26] S. Azhar, W.A. Carlton, D. Olsen, I. Ahmad, Building information modeling for sustainable design and LEED $^{\circledR}$ rating analysis, Autom. Constr. 20 (2011) 217-224, https://doi.org/10.1016/J.AUTCON.2010.09.019.

[27] E. Krygiel, B. Nies, Green BIM: Successful Sustainable Design with Building Information Modeling, (2008) (9780470239605).

[28] A. Gökgür, Current and Future Use of BIM in Renovation Projects Ata Gökgür, Chalmers University of Technology, 2015, http://publications.lib.chalmers.se/ records/fulltext/218421/218421.pdf (accessed November 13, 2018).

[29] S. Azhar, J.W. Brown, A. Sattineni, A case study of building performance analyses using building information modeling, Proceedings of the 27th International Symposium on Automation and Robotics in Construction (ISARC-27), Bratislava, Slovakia, 2010, https://doi.org/10.22260/ISARC2010/0023.

[30] Z. Liu, M. Osmani, P. Demian, A. Baldwin, A BIM-aided construction waste minimisation framework, Autom. Constr. 59 (2015) 1-23, https://doi.org/10.1016/J. AUTCON.2015.07.020.

[31] H.-Y. Chong, C.-Y. Lee, X. Wang, A mixed review of the adoption of building information modelling (BIM) for sustainability, J. Clean. Prod. 142 (2017) 4114-4126, https://doi.org/10.1016/J.JCLEPRO.2016.09.222.

[32] M. Rouse, What Is Application Program Interface (API)? https:// searchmicroservices.techtarget.com/definition/application-program-interface-API, (2017) , Accessed date: 13 November 2018

[33] MuleSoft, What is an API? (Application Programming Interface), https://www. mulesoft.com/resources/api/what-is-an-api, (2018), Accessed date: 13 November 2018.

[34] Autodesk Knowledge Network, What Can You Do with the Revit Platform API? https://knowledge.autodesk.com/pt-br/support/revit-products/learn-explore/ caas/CloudHelp/cloudhelp/2018/PTB/Revit-API/files/GUID-154AB430-AC954CA7-B24A-BE56380B9D86-htm.html, (2018) (accessed November 13, 2018).

[35] A.H. Oti, W. Tizani, BIM extension for the sustainability appraisal of conceptual steel design, Adv. Eng. Inform. 29 (2015) 28-46, https://doi.org/10.1016/J.AEI 2014.09.001.

[36] A.H. Oti, W. Tizani, F.H. Abanda, A. Jaly-Zada, J.H.M. Tah, Structural sustainability appraisal in BIM, Autom. Constr. 69 (2016) 44-58, https://doi.org/10.1016/J AUTCON.2016.05.019.

[37] S.M.S.A. Pereira, S.R.L. Amorim, O desenvolvimento de ferramenta de verificação de requisitos de projeto para o Revit ${ }^{\circledR}$ através de API (The development of a design verification tool for Revit ${ }^{\circledR}$ through API), ENCONTRO NACIONAL DE TECNOLOGIA DO AMBIENTE CONSTRUÍDO, 12-14 Novembro, Maceió, Brazil, 2014, pp. 2954-2963, , https://doi.org/10.17012/entac2014.591.

[38] J.B. Kim, W. Jeong, M.J. Clayton, J.S. Haberl, W. Yan, Developing a physical BIM library for building thermal energy simulation, Autom. Constr. 50 (2015) 16-28, https://doi.org/10.1016/J.AUTCON.2014.10.011.

[39] S. Kota, J.S. Haberl, M.J. Clayton, W. Yan, Building information modeling (BIM)based daylighting simulation and analysis, Energy and Buildings. 81 (2014) 391-403, https://doi.org/10.1016/J.ENBUILD.2014.06.043.

[40] F. Jalaei, A. Jrade, Integrating building information modeling (BIM) and LEED system at the conceptual design stage of sustainable buildings, Sustain. Cities Soc. 18 (2015) 95-107, https://doi.org/10.1016/J.SCS.2015.06.007.

[41] J.C.P. Cheng, L.Y.H. Ma, A BIM-based system for demolition and renovation waste estimation and planning, Waste Manag. 33 (2013) 1539-1551, https://doi.org/10. 1016/J.WASMAN.2013.01.001.

[42] A.R. Justi, Implantação da plataforma Revit nos escritórios brasileiros (Revit platform deployment in Brazilian offices), Gestão \& Tecnologia de Projetos. 3 (2008) 140-152, https://doi.org/10.4237/gtp.v3i1.56.

[43] G. Gourlis, I. Kovacic, Building information modelling for analysis of energy efficient industrial buildings - a case study, Renew. Sust. Energ. Rev. 68 ( (2017) 953-963, https://doi.org/10.1016/J.RSER.2016.02.009.

[44] F. Jalaei, A. Jrade, An automated BIM model to conceptually design, analyze, simulate, and assess sustainable building projects, Journal of Construction Engineering. Vol. 2014 (2014) 1-21, https://doi.org/10.1155/2014/672896. 